\title{
OXIDATIVE DEGRADATION RATE OF PHENOL IN AN UNDIVIDED BIPOLAR ELECTROLYZER
}

\author{
MASAO SUDOH, TAKAMASA KODERA, HARUYOSHI HINO \\ AND HIROSHI SHIMAMURA \\ Department of Chemical Engineering, Shizuoka University, Hamamatsu 432
}

Key Words: Electrolysis, Oxidative Degradation, Phenol, Bipolar Electrolyzer, Energy Consumption

\section{Introduction}

The effect of anodic and cathodic reactions of a bipolar electrode on the oxidative degradation of phenol in an undivided bipolar electrolyzer was reported in the previous paper. ${ }^{3)}$ The purpose of this work is to clarify the change in product concentration and COD with total coulombs under various conditions of electrolysis. The relationship between energy consumption for reducing the COD and operating conditions will also be discussed.

\section{Experimental}

The experimental apparatus was the same as described in the previous paper. ${ }^{3)}$ Nitrogen was supplied to a solution containing phenol at $1.4 \mathrm{~cm} \cdot \mathrm{s}^{-1}$ while oxygen was employed when the solution contained ferrous ions with phenol. The solution temperature was raised gradually with time to several degrees above the $293 \mathrm{~K}$ starting temperature for most experiments. When electrolysis was conducted in a solution of $6.8 \mathrm{~S} \cdot \mathrm{m}^{-1}$ under oxygen sparging, the temperature was raised to $318 \mathrm{~K}$ at the final stage. Electrolysis was also conducted with a pair of flat-plate graphite electrodes $(70 \mathrm{~mm} \times 45 \mathrm{~mm} \times 5 \mathrm{~mm})$ at a distance of $30 \mathrm{~mm}$, located in a cylindrical cell containing $0.3 \mathrm{dm}^{3}$ of the same solution as control.

\section{Results and Discussion}

Figure 1 shows the product concentration, the $\mathrm{COD}$, the amperage, the solution $\mathrm{pH}$ and the electrical conductivity as functions of the normalized amount of electricity for sparging nitrogen gas. By using the equivalent circuit model, ${ }^{3}$ the difference between anodic potential and cathodic potential of a bipolar plate electrode, $E_{B}$, was evaluated to be $1.9 \mathrm{~V}$ at a terminal voltage of $50 \mathrm{~V}$. The total amount of electricity passed was normalized by the theoretical amount of electricity $Q_{T}$ given by the following equation: $:^{4}$

Received February 3, 1988. Correspondence concerning this article should be addressed to M. Sudoh. T. Kodera is now at Nippon Steel Co., Ltd., Tokai 476.

$$
Q_{T}=2 \boldsymbol{F} V(\mathrm{COD})_{0} / 16
$$

The concentration of phenol decreased with increasing amount of electricity and reached almost zero at $Q / Q_{T}$ of 0.25 or more. The COD decreased sharply at the early stage of electrolysis, while the decomposition rate decreased with time. Meanwhile, the concentration of oxidized products increased to their maxima with the increase of total coulombs. It was found that $p$-quinone produced by anodic oxidation of hydroquinone was reduced to hydroquinone when nitrogen was sparged into the solution, probably due to by stimulation of mass transfer from the bulk of solution to the cathode surface. Therefore, it was concluded that introduction of nitrogen gas into an undivided cell was inapplicable.

Figure 2 shows the product concentration and other factors as functions of the normalized amount of

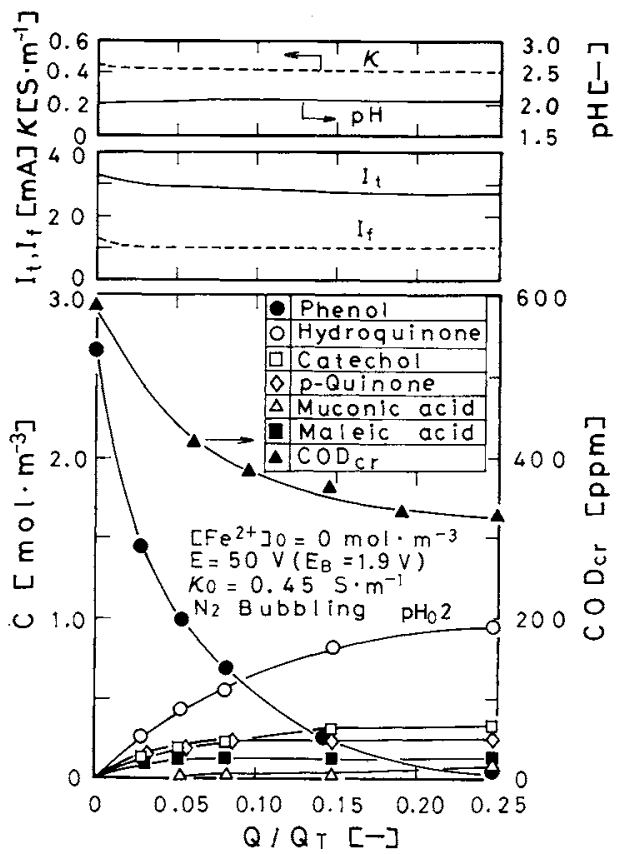

Fig. 1. Relationship of product concentration, COD, amperage, $\mathrm{pH}$ and electrical conductivity of solution to normalized amount of electricity under nitrogen gas sparging at $E=$ $50 \mathrm{~V}$ 


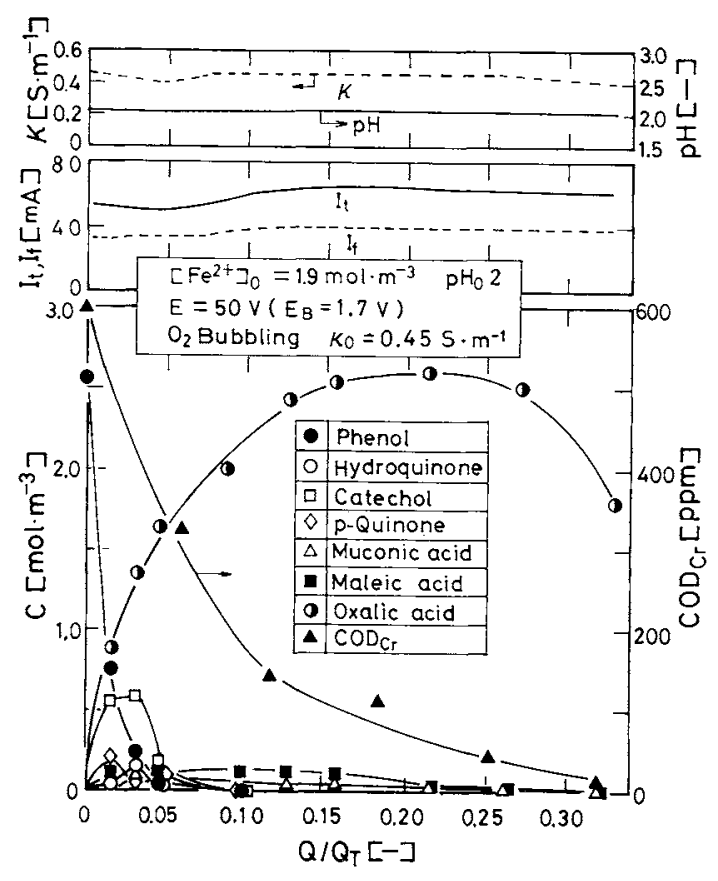

Fig. 2. Relationship of product concentration, COD, amperage, $\mathrm{pH}$ and electrical conductivity of solution to normalized amount of electricity under oxygen gas sparging at $E=$ $50 \mathrm{~V}$

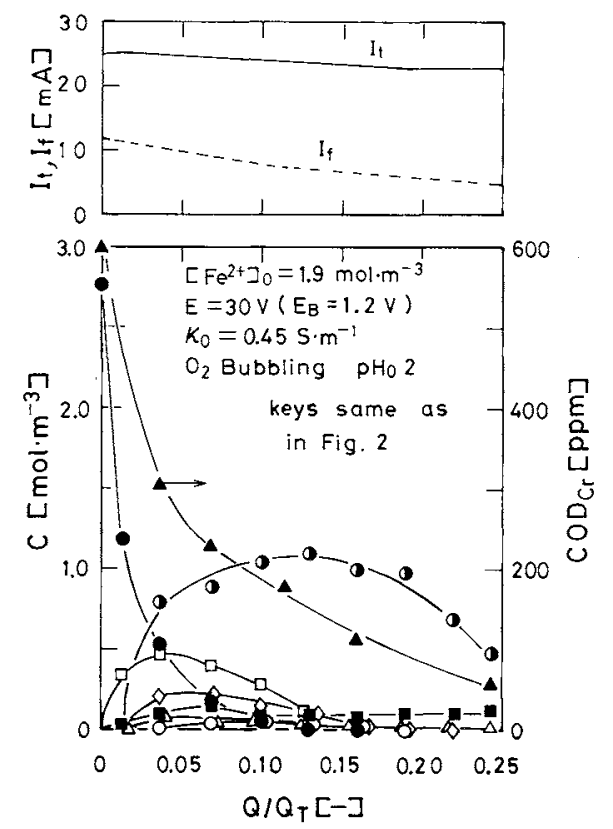

Fig. 3. Relationship of product concentration, COD and amperage to normalized amount of electricity under oxygen gas sparging at $E=30 \mathrm{~V}$

electricity under oxygen sparging at $E=50 \mathrm{~V}$ or $E_{B}=$ $1.7 \mathrm{~V}$. Phenol was destroyed almost completely by electrolysis with $Q / Q_{T}>0.05$. Only oxalic acid was found in the solution and more than $95 \%$ of the COD components was decomposed by electrolysis at $Q / Q_{T}>0.3$. Addition of sulfuric acid into the catholyte of a divided H-type cell was necessary to control the solution $\mathrm{pH}$, since otherwise the proposed reac-

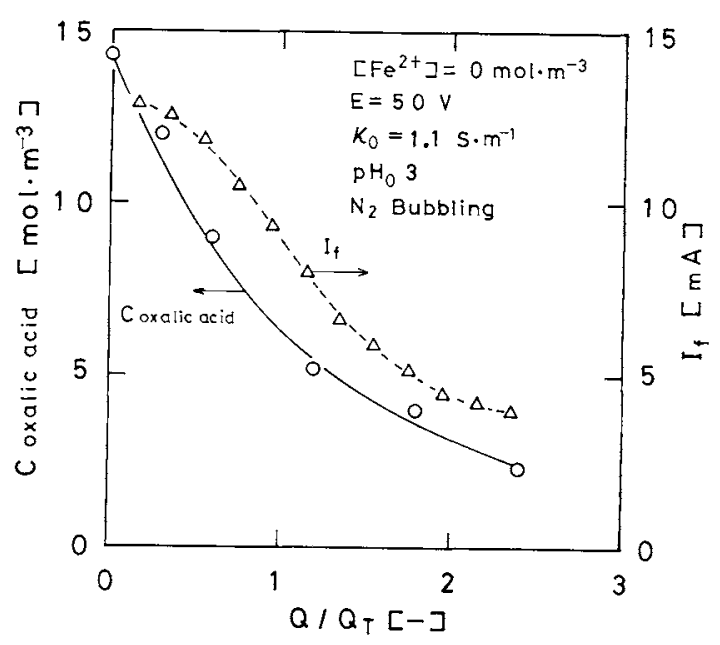

Fig. 4. Relationship of concentration of oxalic acid and Faradaic current to normalized amount of electricity under nitrogen gas sparging

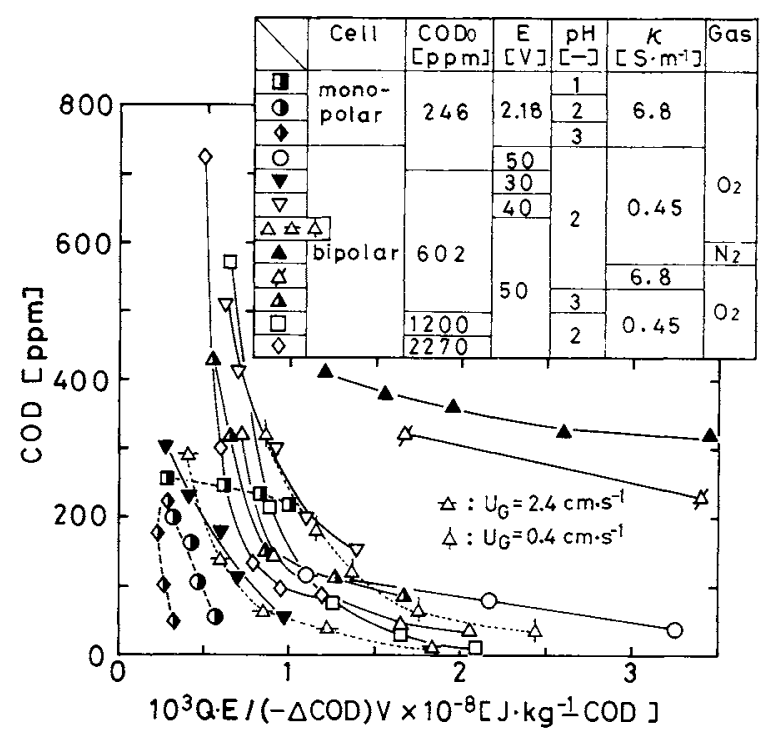

Fig. 5. Energy consumption for reducing COD under various conditions of electrolysis

tion was affected. $\left.{ }^{4}\right)$ With an undivided cell, on the other hand, the $\mathrm{pH}$ did not change during electrolysis since the charge transfer of proton at the cathode was almost equal to the formation rate of proton at the anode.

Figure 3 shows the results at $E=30 \mathrm{~V}$ or $E_{B}=1.2 \mathrm{~V}$. The decomposition rate of phenol with respect to total coulombs at $E=30 \mathrm{~V}$ was smaller than that at $E=50 \mathrm{~V}$, but the concentration of oxalic acid was decreased by decreasing the cell voltage. Carboxylic acids formed by chemical oxidation of the effluent containing organic compounds were difficult to decompose with Fenton's reagent. ${ }^{1)}$ Oxalic acid was decomposed by electrochemically generated Fenton's reagent while the reaction rate was low. $\left.{ }^{4}\right)$ It was reported by Fukuda $^{21}$ that oxalic acid was oxidized effectively by electrolysis with the $\beta-\mathrm{PbO}_{2}$ anode. The 
concentration of oxalic acid was also decreased by anodic oxidation using graphite electrode as shown in Fig. 4. Since the contribution of anodic oxidation to oxidative degradation at $E_{B}=1.2 \mathrm{~V}$ was larger than that at $E_{B}=1.7 \mathrm{~V}$, as indicated in the previous paper, ${ }^{3)}$ the electrolysis condition of $E_{B}=1.2$ was found to be effective for complete degradation of phenol.

Figure 5 shows the energy consumption for reducing the COD. Since the bypass current flowed in the electrolyte phase, the energy consumption of a bipolar cell was larger than that of a single cell with a pair of flat electrodes. The energy consumption decreased with increasing oxygen velocity and was minimized to $1 \times 10^{8} \mathrm{~J}$ per $\mathrm{kg}$-COD for the reduction of the COD to $50 \mathrm{ppm}$ under the most suitable condition. The bipolar electrolyzer having a vertical stack of perforated electrodes was found to be effective in scaling up the electrolyzer.

Nomenclature

$C \quad=$ concentration $\quad\left[\mathrm{mol} \cdot \mathrm{m}^{-3}\right]$
$\begin{array}{ll}E & =\text { cell voltage } \\ E_{B} & =\text { difference betw }\end{array}$ cathodic potentiat of

$\begin{array}{lll}\boldsymbol{F} & =\text { Faraday's constant } \quad\left[\mathrm{C} \cdot \mathrm{mol}^{-1}\right]\end{array}$

$I_{f} \quad=$ Faradaic current $\quad[\mathrm{A}]$

$I_{t} \quad=$ total current $\quad[\mathrm{A}]$

$Q \quad=$ total coulombs [C]

$Q_{T} \quad=$ theoretical coulombs defined by Eq. (1) [C]

$u_{G} \quad=$ gas velocity $\left[\mathrm{m} \cdot \mathrm{s}^{-1}\right]$

$V \quad=$ volume of reactant solution $\quad\left[\mathrm{m}^{3}\right]$

$\kappa=$ electrical conductivity of solution $\quad\left[\mathrm{S} \cdot \mathrm{m}^{-1}\right]$

$\langle$ Subseript $\rangle$

$0 \quad=$ initial value

\section{Literature Cited}

1) Fukuda, T.: The 16th Kenkyu Koryu (Research Exchange) Seminar, p. 34 (1982).

2) Hagiwara, K.: PPM, 13(6), 16 (1982).

3) Sudoh, M., T. Kodera, H. Hino and H. Shimamura: $J$. Chem. Eng. Japan, 21, 198 (1988)

4) Sudoh, M., T. Kodera, K. Sakai, J. Q. Zhang and K. Koide: J. Chem. Eng. Japan, 19, 513 (1986).

\section{A NEW SOLUTION TO THE PROBLEM OF NONISOTHERMAL GAS ABSORPTION IN A PACKED TOWER}

ISAMI YOSHIFUKU

Department of Chemical Engineering, Kagoshima University, Kagoshima 890

Key Words: Absorption, Packed Tower, Flowgraph, Computer Simulation, Sequential Cell

Solutions to the design problem of nonisothermal packed gas absorber, based on graphical and computational techniques, were well developed by several investigators ${ }^{1-6)}$ during the $1970 \mathrm{~s}$. In these researches, a major effort has been made to establish a model in which the physical property data, the resistance in gas phase and/or liquid phase, and the heat effects e.g. heat of solution, latent heat of vaporization and sensible heat transfer in both phases are of significance.

In this report, a new solution based on flowgraph representation is presented for the purpose of computer simulation of a packed tower process.

\section{Problem Statement}

In the flowgraph construction, the following as-

Received September 21, 1987. Correspondence concerning this article should be addressed to I. Yoshifuku. sumptions are made:

1) adiabatic gas absorption in a packed tower with ammonia-air-water system is treated.

2) liquid-phase resistance to heat and mass transfer are ignored and the influence of solvent evaporation is accounted for.

3) heat of solution, latent heat of vaporization and molar specific heat are constant.

The problem calls for the determination of tower height from the data of tower bottom, tower top, physical properties and volumetric heat and mass transfer coefficients.

\section{Sequential Cell Flowgraph Construction}

An algorithm for the problem of the packed tower process has previously been reported, ${ }^{71}$ along with a detailed procedure of sequential cell flowgraph construction. In brief, the procedure consists of tabu- 